\title{
Task-based Instruction and Vocabulary Learning: A Comparative Study of Jigsaw and Information Gap Tasks on Vocabulary Learning
}

\author{
Hooshang Khoshsima \\ English Language Department, Chabahar Maritime University, Chabahar, Iran \\ E-mail: khoshsima@cmu.ac.ir \\ Amin Saed (Corresponding author) \\ English Language Department, Chabahar Maritime University, Chabahar, Iran \\ E-mail: Amin.Saed@cmu.ac.ir
}

Received: 25-04-2016

Published: 01-09-2016
Accepted: 26-06-2016

doi:10.7575/aiac.ijalel.v.5n.5p.228
Advance Access Published: July 2016

URL: http://dx.doi.org/10.7575/aiac.ijalel.v.5n.5p.228

\begin{abstract}
This study investigated Iranian intermediate EFL learners' vocabulary learning within the paradigm of Task Based Language Teaching through instructing jigsaw and information-gap tasks. To this end, 60 intermediate EFL learners were selected. They were all female and their age range was between 16-17 years old. Then the experimental groups in which one group with the use of jigsaw and one with information-gap received task based instruction for one session each week for five weeks, while the control group experienced the same amount of instruction as ordinary classes. At the end of the study, all subjects were assigned a 50-item multiple choice vocabulary test. A one-way ANOVA was used to analyze the data. The results indicated that TBI had a significant effect $(p=.000<.05)$ on promoting vocabulary knowledge of Iranian intermediate EFL learners; there existed a significant difference between the experimental groups' performances in the assigned tests, as well. The main pedagogical implication of this study is for teachers in that by involving learners in task completion and enjoying the process, learners can improve their vocabulary knowledge and accordingly their language proficiency.
\end{abstract}

Keywords: Task-based instruction, information-gap, jigsaw task, implicit learning, explicit learning

\section{Introduction}

Vocabulary acquisition plays a vital role in learning languages. It is a fundamental component of language proficiency and provides much of the basis for how well learners listen, speak, write and read (Richards \&Renandya, 2002). In past years, this part of language teaching was neglected and it was due to the thought that vocabulary could be left to take care of itself. Recently numerous studies have investigated English learning and most emphasized the importance of vocabulary learning (Decarrico, 2011). As Wilkins (1976) stated, without grammar very little can be conveyed but without vocabulary nothing can be understood. He also pointed out the importance of vocabulary in communication. Insufficient vocabulary knowledge or vocabulary difficulty results in communicational failure. Having good language skills is very important in order to have fluent communication. These skills include listening, speaking, reading and writing. Huckin, Haynes and Coday (1993) indicated that reading ability and vocabulary knowledge are two of the most important components of performance on second language and depend on another one. Poor vocabulary knowledge leads to misunderstanding and consequently unsuccessful communication. By developing the knowledge of vocabulary, achieving communicative competence in a second language can be enhanced. It is part of every language skill and improving it leads to the enhancement of communicative competence. It also has a strong impact on reading comprehension and as it is obvious, without comprehension, there is no learning.

Based on National Reading Panel (NICHD, 2000), vocabulary is identified as one of five major components of reading: phonemic awareness, phonics, reading fluency, vocabulary development and reading comprehension.

So people with larger vocabularies tend to be better readers. Learners' difficulty in reading comprehension in some part is connected to their lack of word knowledge. The importance of vocabulary knowledge to overall language learning success and more specifically to reading comprehension is documented (Anderson \& Nagy, 1991 Baker, Simmons, \& Kame-ennui, 1998).

The low status of vocabulary mostly was due to the language teaching approaches that were based on American linguistic theories. These approaches emphasized grammatical and phonological structure. Approaches of that time paid systematic attention to basic sentence patterns because they believe that grammar should be the starting point of language learning. In these approaches in fact vocabulary learning receives no attention. With the advent of generative 
linguistic in 1960s, there was a shift in linguistic theory but still little challenge to the secondary role of vocabulary. Approaches based on generativist just give more importance to vocabulary (Carter \& McCarthy, 1988: as cited in Decarrico, 2011). With the emergence of communicative competence of Hymes in 1972, language teaching pedagogy has experienced approaches such as communicative language teaching and so on. As Smith (2000) pointed out such approaches promoted fluency over accuracy and there was a shift of focus to discourse level but still again vocabulary was given secondary role.

Recently vocabulary studies and researchers have developed and more emphasis is put on the role of vocabulary knowledge while learning another language. According to Zimmerman (as cited in Decarrio, 2001), in the 1980s there has been a reorientation in language description which has led many scholars to rethink of language and the role of vocabulary. The result of these studies was the debate over whether vocabulary should be taught explicitly or implicitly.

Interest in such psycholinguistic processes of vocabulary learning led to studies about developing more effective vocabulary teaching and learning strategies (Marianne Celce-Murica, 2001). Among these approaches communicative approach led to a focus on implicit learning.

While in explicit learning students engage in vocabulary activities, in implicit learning mind is focused elsewhere and vocabulary is learnt incidentally (Murcia, 2001).Due to the emergence of communicative approaches we have task based language teaching and as Willis(1996) pointed out it is the development of communicative language teaching. It is believed that task provide learners with a natural context (Nunan, 1989). Task gives abundant opportunity of interaction to learners and through which they learn language (Freeman, 2003).

Despite the fact that many tasks have been designed for pedagogic purposes, it is only in recent years that language teaching researches have shown tendency in working what kinds of tasks can improve language learning process. As Prabhu (1987) indicates, there are three major types of tasks according to the type of cognitive activity involved. They are; information-gap tasks, reasoning gap tasks and jigsaw tasks. This study tries to investigate the role of the first one and the third task on learning and recalling vocabulary.

\subsection{Statement of the problem}

Recently because of the importance of vocabulary knowledge, much more focus has been put on the studies and researches regarding vocabulary learning. The most effective procedures that second language learners use to retain the vocabulary are not still clear (Sanaoui, 1995). As the results of most language tests offer, vocabulary is one of the toughest areas of language to be learnt and the easiest area to be forgotten. The area demands great efforts on the part of the learners who must retain the new words that they hear or see to be able to bring them into use.

However, what plays the most vital role in helping learners successfully retain and remember new words is the type of instruction they receive by the language teacher. While some language teachers provide the learners with list of new words and ask them to memorize such long lists, some others engage their learners in vocabulary learning process by asking them to read intensive texts, talk about the definition of new words in their small groups and provide some examples of the word.

Despite the works that have been done in the case of alleviating the problem of vocabulary learning and teaching, there are still learners who have serious problems with learning and retaining vocabularies. Whereas some think of the participatory approaches such as task-based ones (negotiating word meaning) to be more effective than classical approaches (translating words for learners), the results of some studies reveled the superiority of translation learning in terms of quantity (Prince, 1996). On the other hand, some researches proved that learners look for equivalences of meaning even when the contexts in which the words are used in different languages clearly diverge (McCarthy, 1992) .

Due to the importance of vocabulary knowledge and its contribution to the mastery of other skills of language learning, especially its close relevancy to reading comprehension, the researcher decided to conduct this study in order to investigate the role of task (most importantly information-gap task and jigsaw task) on learning and retaining vocabulary to see whether it can help learners in better learning and retention of them in comparison to learning them through classical techniques. The research attempted to examine the following question:

Do jigsaw and information gap tasks have any significant impact on learning and retaining vocabulary of Iranian EFL learners?

\section{Literature review}

Vocabulary teaching and learning is a constant challenge for both teachers and students because historically minimal attention has been paid to vocabulary instruction in teaching English as a second language(ESL) classroom. For years, the familiar methodology for learning a second language was first to pay attention to grammar and sentences and then to vocabulary. In fact grammar was viewed as the main task and mastery of its structures was the primary goal in second language acquisition (SLA). In contrast vocabulary development was approached as some kind of auxiliary activity while it is important in expressing ideas and thoughts. Vocabulary knowledge is essential when using a foreign language since no one is able to communicate without words. Wilkins (1976), verifies the importance of vocabulary in communication. He declared insufficient vocabulary will results in communication barriers or failures; without the mediation of vocabulary no grammatical or other types of linguistic knowledge can be employed in second language, communication or discourse. Nation`s statement (cited in Nation and Waring,1997) also explained its importance; "vocabulary knowledge enables language use, language use enables the increase of vocabulary knowledge, knowledge of the world enables the increase of vocabulary knowledge, language use and so on(p.6). The crucial role that lexis 
plays in second language learning and teaching has been repeatedly recognized in theoretical and empirical second language acquisition (SLA) vocabulary research.

Hence, in the introduction of his seminal book on the mental lexicon, Singleton states that "the major challenge of learning and using a language- whether as L1 or as L2- lies not in the area of the broad syntactic principles but in the "nitty- gritty" of the lexicon" (Singleton, 1999, p. 4), an idea which is also shared by Hunt and Beglar (2005, p. 2), who argue that "the heart of language comprehension and use is lexicon".

Other authors have gone even further in debating that "the single most important task facing language learners is acquiring a sufficient large vocabulary" (Lewis, 2000, p. 8), or that the most noticeable difference between native speakers and foreign learners is in the amount of vocabulary they know or in their word knowledge (Laufer, 1998). From perspective of pedagogy, questions have developed around the "what" and "how" of vocabulary teaching (Read J., 2004). Much attention has been allocated to verifying the best pedagogical practices in improving students' lexical development. A general discussion in SLA research is related to the nature and function of explicit and implicit learning processes (Sanchez \& Manchonn, 2007); one issue is whether or not implicit attention in vocabulary acquisition is necessary (Nation P. , 2005 ;Coday \& Huckin, 1997). The general agreement seems to be a compromise between explicit and implicit lexical instruction. The former would be implemented through activities such as the study of decontextualised lexis, the use of dictionaries and so on (Hunt \& Beglar, 2005), while implicit instruction would involve engaging students in language use activities, especially reading and listening. In fact Nation (2005, p. 585) summerized it in his own declaration that " every course should involve some deliberate attention to vocabulary as well as opportunities to meet the words in meaning-focused use".Consequently, through the evolution of language teaching and learning methods and approaches, vocabulary came to its own. TBLT with a focus on employing authentic material, involving learners in real-like activities and enjoying the support of some robust perspectives tend to significantly promote EFL vocabulary knowledge.

Richards and Rodgers (2001) indicated that task-based instruction tries to teach vocabulary both directly and indirectly in a natural context. Vocabulary like other aspects of language learning can be facilitated when done via cooperative learning.

It is indicated that leaning vocabulary is a very learner-centered activity (Mehring, 2005). Many done researches, proved that learners in a cooperative atmosphere learn better because they feel more relaxed and learn more from peers since making mistakes is accepted and it can be fun.

\subsection{Vocabulary teaching strategies}

Over the last decades, researchers have shown that vocabulary teaching plays an important role in comprehending what language learners read and in what they write or say (McCarthy, 1992). It is important to know which vocabulary technique is the most effective and advantageous one. Vocabulary instruction includes different techniques ranging from translation of word and giving definitions to filing in the gaps and matching. Each technique also consists of different stages of practice to fix the words in the learners` mind.

Generally, this instruction consists of various strategies. In this research, the researcher is going to examine the impact of two kinds of techniques. One is classical method and its classical techniques and the other one is the use of taskbased instruction, mostly information-gap and jigsaw one which involves learners in the process.

Task can be as broad as mastering a second or foreign language or as specific as recalling the meaning of a word. For instance, in vocabulary learning process, learning a word in a word list is different from learning the same word in a passage.

It also must be noted that remembering a word meaning is completely different from being able to use the same word in real life situation. Therefore, the researcher is going to show which method is superior to the other, and is more effective in helping learners to be able to use the learned words in such situations.

\subsubsection{Translation}

Translation requires no demand on the part of instructor to teach as well as learners to learn a new word. Translation as a technique of teaching new words to the second and foreign language learners may be regarded as a simple technique, but there arouse a big question in regard of its efficiency, whether it works or not. The most important aim of learning a new word is being able to use the same word in the upcoming situations.

\subsubsection{Using dictionary}

There has been a debate of whether a dictionary should be used in the second or foreign language classroom between language teachers and researchers. Empirical researches on the impact of using dictionary on vocabulary learning have focused on the comparison between the usefulness of dictionaries and that of guessing (Knight, 1994). Generally, results of these studies favored the contextual guessing approach (Crist, 1981). However, in recent years researchers have witnessed a shift of interest in dictionary research in L2 context, for example (e.g. Hulstijn, 1996; Knight, 1994; Laufer, 1998). In 1994(Knight) found that while incidental vocabulary learning through contextual guessing took place, those learners who had used a dictionary had not only learned more words immediately after reading but also could remember the words more after two weeks.

The advantage of using dictionary was confirmed to be true in a study of 293 Japanese EFL university students done by Luppescu \& Day (1993). Their participants were randomly assigned to a treatment (dictionary group) and a control 
group. Participants were asked to read a short story in class. The treatment group used a bilingual dictionary and the control one was not permitted to use any.

Then both groups were tested and the results suggested an advantage for treatment group in learning vocabulary, but they took almost twice as long to read the text as did control group. Therefore, it is not crystal clear whether using dictionary is beneficial or not.

\subsubsection{Memorization of word lists}

One of the other techniques of learning a new word is the memorization of the new words, although it seems to be more a stage of doing exercise for putting words in mind rather than a technique of learning. Learners simply repeat new words until they can recognize them. It seems that not only researchers have not done enough research in this field but also most of researches that have been done in this area were carried out before 1970s.

\subsection{Vocabulary in Task-Based Approach}

Task-base language teaching can be regarded as a recent version of communicative methodology. Its application dates back to two main projects: Malaysian communicational project and Bangalore project (Richards \& Rodgers, 2001). The role of TBLT has gained more support by scholars such as Long and Crooks (1992) who were interested in pedagogical application of second language acquisition theory.

They believed that this methodology received more attention in mid-1980s as a SLA research tool. It also was believed that engaging learners in tasks provides a better context for activation of learning processes and hence provides a better condition of language learning to take place. As it was mentioned, TBLT is considered to have common principles with communicative language teaching(CLT) but here the main importance is given to the task as the central unit of instruction. In TBLT and other methods derived from CLT learners use English to learn it (Freeman, 2003). These approaches, as Skehan(1998) argues, emphasized the meaning and tasks are assessed based on their outcomes.

\subsubsection{Task types and their characteristic}

In TBLT literature, there are many kinds of task categories since TBLT has been considering a vogue in language teaching field; writers have studied it from different outlooks. The Bangalore project, one of the earliest curricular applications of TBLT, provides three principal task types: information gap, reasoning gap, and opinion gap.

Another typology that appeared almost at the same time was proposed by Pattison as' questions and answers, dialogues and role plays, matching activities, communication strategies, pictures and picture stories, puzzles and problems and discussions and decisions (Nunan, 2006, p.56). Willis proposed six task types termed: listing, ordering, sorting, comparing, problem solving, sharing personal experiences, and creative tasks (Richards \& Rodgers, 2001, p. 234). Lately, Richards has proposed five pedagogical tasks, namely, jigsaw tasks; information-gap tasks; problem-solving tasks; decision-making tasks, and opinion exchange tasks (quoted in Nunan, 2006, p. 58).

Robinson (1991) looked at task characteristics differently and suggested three groups of factors that are important in designing tasks. He distinguished "task complexity that depends on cognitive demand of tasks", "task difficulty that depends on learner factors such as aptitude, confidence, motivation, etc., and "task conditions that depends on the interactive demands of tasks" , such as familiarity of participants and whether tasks demand one-way or two-way information exchange (p. 287).

He argues that these factors influence task performance and learning. Comparing to the other groupings listed above, Richard's categories contains following advantages: 1) items in the group are distinct from one another; 2) it is easier to understand the content of tasks based on their names; 3) they covers different characteristics of tasks (Song Vanlu, 2011). Therefore, his definition was used in the present study.

Since tasks have been classified into various categories, it is necessary to know how to compare them. Pica et al propose that tasks are distinct from or connected with regard to the following features: 1) One-way or two-way: whether there is mutual exchange of information among participants when tasks are carried out. 2) Convergent or divergent: whether participants achieve the same goal or different goals. 3) Collaborative or competitive: whether participants carry out a task in a cooperative or competitive fashion. 4) Single or multiple outcomes: whether there is only one or multiple outcomes are possible. 5) Concrete or abstract language: whether the language used in the task is concrete or abstract. 6) Simple or complex processing: whether it is required a simple or complex cognitive process to complete a task. 7) Simple or complex language: whether task completion requires simple or complex language use. 8) Realitybased or not reality-based: whether the task related to real-life tasks (Richards \& Rodgers, 2001, p. 235).

\subsection{Previous research on TBLT}

"Tasks do not take place in a vacuum; nevertheless, until recently, much of the task-base learning and teaching literature has had a tendency to treat them as if they did. Few studies have taken place in intact classes (Samuda, 2001). Yuan and Ellis conduct a study concerning the effect of time limit of a task on learners' performance in terms of their linguistic complexity and accuracy.

The results show that learners who are given unlimited time to perform are required to perform the same task under time pressure (quoted in, 2006, p. 27). Foster and Skehan (2006) investigated the influence of task types and task planning on linguistic fluency, accuracy and complexity. They found that planning influences learners 'outcome in terms of fluency and complexity, but not on accuracy (Oxford, 2006). There also are some other studies demonstrating the connection between task itself and learners` vocabulary acquisition, which are similar to the present study. Ellis and 
Heimbach investigated the relation between meaning negotiation and comprehension, demonstrating that the task with opportunity to interaction facilitates children's understanding (Bygate et al, 2001). As cited in Ellis (2001) "Ellis (1994) investigated the influence of different types of task input on comprehension of directives containing target words. The results of this study showed that learners receiving modified input outperform their counterpart with simplified input on vocabulary acquisition", (p.60). Newton went a step further and compared the impact of different types of task on vocabulary acquisition, demonstrated that a split information task results in more vocabulary gain (quoted in Ellis, 2003, p.87).

\section{Method}

\subsection{Method and design of the study}

This study was set out to explore whether applying TBI to intermediate Iranian EFL learners has any influence on improving their vocabulary knowledge or not and make them ready to encounter real world out of classroom for effective communication. Furthermore, it made a comparison between the effect of jigsaw task and information-gap.

It is a quantitative study as it was done to compare the effects of TBI on the subjects 'vocabulary knowledge and to find out the difference between the influences of two kinds of tasks on learners of this study. Furthermore, it aimed to scrutinize subjects` attitudes toward implemented tasks.

Sixty intermediate EFL learners were selected and assigned into three different groups, two experimental ones and a control one. They were all female and their age range was between 16-17 years old. Prior to the study, all subjects were given a TOEFL the proficiency test to ensure their level as intermediate language learners. The participants who scored at the intermediate level, based on the point scale of TOEFL test, entered the experiment.

The next pre-test, which learners took, was a vocabulary test based on course materials (English Book 3). According to what Song (2011) has done, the aim of this pre-test was to indicate the unknown words to the researcher. Then the "experimental groups", (one group with the use of jigsaw and one with information-gap) received task based instruction for one session each week for five weeks, while the "control group" experienced the same amount of instruction as ordinary classes. After each session, the experimental groups were tested with an immediate posttest. The delayed posttest was held some days after completing the instruction.

It is suggested that several-day lapse will allow the items of test to be forgotten so that pupils will not recognize them when they are encountered (Hulstijn, 1996, p. 351). The aim of these posttests was to investigate the degree of difference between tasks' impacts on learning vocabulary. Finally, at the end of instruction, all of the subjects in the experimental groups and control one were post-tested through a multiple choice vocabulary test.

\subsection{Participants}

All participants of this study were Iranian female EFL learners between the age ranges of 17-18 and were native speakers of Persian who were participating in English classes of third grade of high school at Shahid Dastgheyb high school in Shiraz, Fars.

All the subjects had had the same amount of exposure to materials before the experiment and all of them had studied English in the same school. Therefore, they were judged to be almost at the same level of language proficiency, namely intermediate level of English proficiency: however, their level was established via implementing TOEFL proficiency test. They were 60 randomly chosen high school students who were divided into three groups: 20 in control group, 20 in jigsaw and 20 in information-gap group. The list of unknown words to be worked on through the instruction was ensured by the use of vocabulary word list as the pre-test. This study involved just females, so gender difference was not considered in this study.

\subsection{Treatment procedure}

The instructional part of this study was conducted on Thursdays as extra classes for third-grade female high school students. None of the subjects was informed about the aim of these classes. First of all, authorities of the high school asked the researcher to observe regular English classes of high school in order to get familiar with routines of such classes to be able to conduct control group as well as possible. Subjects were put into three classes and it was done randomly without any bias, but before administrating the TOEFL and vocabulary test, they were not aware of these classes. After ensuring their homogeneity, the students were informed about groups and were told which class they had to attend. They were put into two experimental groups and one control group. All the classes consisted of twenty subjects.

All the subjects in groups received the same amount of materials, only the treatment was different. The experimental groups attended separate sessions before starting classes in order to be justified about tasks and how the techniques should be done. The first group was called group A (the jigsaw group), the second one B (the information-gap group) and the third one group C (control group). Group C worked on vocabularies with ordinary traditional method.

Almost 10 new words were worked on in each session and this was done in all groups. Every session took about 90 minutes; nearly 30 to 35 minutes of every session was spent on vocabulary teaching. In experimental groups, target words that might have facilitated subjects` task completion were presented on board with their definitions and sample sentences. The instructor pre-taught new words in this phase. It should be mentioned that the definitions and sample sentences written on board were removed during task completion. 
In group A, depending on the segments of the task, students were put either to five groups of four or in pairs. Every student in every group was given a segment, and then temporarily they were put in expert groups with those having the same segment. They were asked to work on their parts in expert groups to become the master of their own part because they were going to get back to their original groups. After participating in expert groups, they returned to their original groups in order to explain their part to the other members of group. Then different pictures were put on the board and each group was asked to write the name of the possible picture, which matched the task, on which they had worked. Mostly in case that they were put in pairs, they received different but incomplete pictures and based on their partner's description they were asked to complete their pictures; finally each group had to choose the best picture which matched the whole description. In fact, when they finished the task they were required to choose one possible picture related to completed task presented on the whiteboard.

In group B, always the teacher himself described the task and gave the description for the incomplete picture. Pupils had to take notes based on the instructor's description in order to use them in completing their pictures. After finishing the task, each pupil was asked to choose the possible picture for the description. The pictures were presented on the board and they were asked to match their own picture with the correct one among those on the board.

\subsection{Instruments}

Three instruments were employed in this study: 1. A TOEFL proficiency test, 2. A vocabulary test based on course materials (English Book 3) and some pictures, 3. SPSS software

\section{Data analysis}

\subsection{Performance of subjects `on TOEFL pre-test}

All subjects took TOEFL proficiency test to ensure they were intermediate EFL learners. Table 1 displays the TOEFL pre-test results. The estimated language proficiency mean of all participants amounted to 435.57 which indicated them as intermediate learners.

Table 1. Results of TOEFL proficiency pre-test

\begin{tabular}{|c|c|c|c|c|}
\hline & $\mathbf{N}$ & Mean & Std. Deviation & Std. Error Mean \\
\hline score & 60 & 435.57 & 39.041 & 5.040 \\
\hline
\end{tabular}

The results of this table indicate that all of the subjects are in the intermediate level $(M=435.57)$ and ready to be put into different groups as control group, information-gap group and jigsaw group.

4.2 Performance of groups in TOEFL proficiency pre-test

After assigning all subjects as intermediate students, the researcher administered the test of homogeneity of variances between groups to ensure their comparability at the beginning of the study. Table 2 presents the result of this test.

Table 2. Test of homogeneity of variances

\begin{tabular}{cccc}
\hline Levene Statistic & df1 & df2 & Sig. \\
\hline .191 & 2 & 57 & .826 \\
\hline
\end{tabular}

In this table the reported sig. is $(P>.05) 0.826>.05$ which is larger than 0.05 . Therefore, there was no significant difference between these groups at the beginning of the instruction and they were comparable.

\subsection{Data Analysis for Research Questions}

The first research question of this study dealt with the impact of TBI on vocabulary learning of intermediate Iranian EFL learners. It was hypothesized that this instruction (TBI) has no significant effect on intermediate Iranian EFL learners` vocabulary learning.

As it was mentioned in the previous chapter of this research, the subjects of this study were put into three groups of twenty. Experimental groups were involved in five task-based vocabulary-learning sessions. The control group benefited the same amount of time and sessions of vocabulary learning practice without being involved in TBI. Every session subjects worked on learning ten vocabularies; experimental groups with the application of jigsaw task and information-gap task and the control group was conducted as ordinary English classes. Every session took 30 to 35 minutes working on ten selected vocabularies. After completion of the whole instruction, all the subjects participated in a multiple choice 50 -item vocabulary test. There were three sets of scores (belonging to control group and two experimental groups) for the vocabulary learning gains of the whole instruction.

All scores were out of 50 for each subject and all the mean scores below were calculated out of 50 as well. One-way ANOVA was inferential statistic run for scores taken from 50 -item vocabulary test. This one-way between subjects ANOVA was conducted to compare the effect of TBI on Iranian intermediate EFL learners' vocabulary learning in jigsaw and information-gap conducted classes and non-TBI conducted class condition. There was a significant effect of 
TBI on learners' vocabulary learning at the $p<.05$ level for the three conditions $F(2,57)=692.55, P=.000)$. Table 3 and 4 reveals these findings.

Table 3. Descriptive statistics for mean difference of groups

\begin{tabular}{lcccccccc}
\hline & N & Mean & $\begin{array}{c}\text { Std. } \\
\text { Deviation }\end{array}$ & Std. Error & $\begin{array}{c}\text { 95\% Confidence Interval } \\
\text { for Mean }\end{array}$ & Minimum & Maximum \\
\cline { 6 - 8 } & & & & \multicolumn{2}{c}{$\begin{array}{c}\text { Lower } \\
\text { Bound }\end{array}$} & $\begin{array}{c}\text { Upper } \\
\text { Bound }\end{array}$ & \\
\hline jigsaw & 20 & 38.85 & 2.007 & .449 & 37.91 & 39.79 & 35 & 42 \\
\hline info gap & 20 & 19.10 & 2.269 & .507 & 18.04 & 20.16 & 15 & 24 \\
\hline control & 20 & 15.10 & 2.198 & .492 & 14.07 & 16.13 & 12 & 20 \\
\hline Total & 60 & 24.35 & 10.683 & 1.379 & 21.59 & 27.11 & 12 & 42 \\
\hline
\end{tabular}

Table 4. ANOVA statistics

\begin{tabular}{lrrrrr}
\hline & df & \multicolumn{1}{c}{ Mean Square } & \multicolumn{1}{c}{ F } & Sig. \\
\hline Between Groups & 2 & 3233.750 & 692.556 & .000 \\
\hline Within Groups & 57 & 4.669 & & \\
\hline Total & 59 & & & \\
\hline
\end{tabular}

Table 3 reveals the mean and standard deviation for jigsaw, Information-gap and control groups. They are reported as $(M=38.85, S D=2.00),(M=19.10, S D=2.26)$ and $(M=15.10, S D=2.19)$ for these three groups respectively. Therefore, the mean score for jigsaw group significantly differs from the other two groups.

The mean score of information-gap group also significantly is different from that of control group but not that much significant like the jigsaw group. Table 4 reveals that there is a significant difference between groups therefore because of statistically significant results, it was needed to compute post hoc test. The Tukey post hoc test was selected. This test compared the TBI and non-TBI conditions. It also compared the two TBI conditions.

The post hoc comparisons using the Tukey HSD test indicates that the mean difference score between jigsaw group and the other two groups is higher. There also is a difference between mean scores of information-gap group and control group.

The results of post hoc test presented a significant difference between TBI classes and control group at the level of $p<.05$. So based on these findings the null hypothesis related to the existence of no difference on learners vocabulary learning based on the use of TBI was rejected; the findings presented in the tables proved the impact of TBI on improving learners' learning and retaining vocabulary.

\section{Discussion\& conclusion}

The mean score results of the implemented one-way ANOVA indicated that the treated groups significantly $(p \leq .05)$ outperformed the control group in the 50-item vocabulary test which was administered to all of the subjects of this study. Therefore, the first null hypothesis was rejected because based on statistics of tables 4 .

3 and 4.4; TBI had significantly affected intermediate EFL learners` vocabulary learning. Moreover, the reported mean and standard deviation scores of the 10-item tests, which were given only to experimental groups after each session, illustrated a significant difference $(p \leq .05)$ between treated groups' performances in these tests. The results of the five performed independent T-tests showed that information-gap pupils outperformed those in the other group worked with jigsaw task. After implementation of one-way ANOVA a post hoc test was also done. The derived statistics of this test showed that there also was a significant difference between the treated groups` performance on this last 50-item test. In fact there was a high mean difference $(M D=19.75)$ between them.

Due to the importance of English as an international language, people rush towards learning this language. Accordingly, research on all aspects of ESL teaching is increasing rapidly, as is demonstrated by publication of a large number of books with this subject all around the world. Many books on this subject would be found in well-stocked bookshops. The role of vocabulary is crucial in language teaching. Recent studies of ESL acquisition suggest a heavy concentration on vocabulary learning, demonstrating that vocabulary is a prerequisite for later proficiency in the language (Thornbury, 2002, p. 160). Various language teaching methods and approaches appeared and after a while of time faded away. Moreover, none of these methodologies noticed the importance of the use of authentic materials or involving learners in the learning process in ESL/EFL context. TBLT with a novel view had a special focus on employing authentic materials, involving learners in task completion and enjoying robust theoretical foundations could have a remarkable effect on successful teaching and learning vocabulary. 
As mentioned before, TBI has enjoyed considerable popularity in different parts of the world during the past two decades. A series of studies of TBLT has been conducted and various articles and theses are published. Many of these studies just investigate the impact of TBLT on language learning. The present study was an attempt to clarify the impact of task-based language instruction on Iranian intermediate EFL learners' vocabulary learning. Moreover, the differences between the impact of the two implemented tasks and their relation with pupils` vocabulary learning and recalling in addition to considering the impact of TBI in vocabulary learning was discussed. In fact at first, it aimed to establish the effect of task-based instruction on vocabulary learning and then to set up which of these two tasks, jigsaw or information-gap, best promoted learners` vocabulary learning and recalling. At last, it investigated the degree of effectiveness of these two tasks on experimental pupils' attitude and motivation towards vocabulary learning. Introduction, the related concepts and studies, the employed methodology and the obtained results, all were discussed and delineated in the previous chapters in detail.

The findings of this study are in agreement with the existing studies in the literature, which revealed that TBI could make better learners' vocabulary knowledge. Besides, this study showed that information-gap task affected recalling vocabulary for a short time while jigsaw task improved long term recalling of vocabulary. Therefore, it also is in line with the findings of all studies showing the usefulness of pupils` involvement in process of learning. Learners were engaged in completing the task especially those who worked with jigsaw task. Due to the nature of this task, pupils are completely involved in task completion and indirectly they learn vocabularies.

According to the results, it can be concluded that the experimental groups outperformed control group due to the TBI utilized for them as the treatment. So it can be justified that tasks are in accordance with the shift toward the utilization of authentic material and learner's involvement. It also should be noted that due to the statistical results, the degree of learners` involvement in task completion is effective in learning and recalling vocabulary.

\section{References}

Crist, R. L. (1981). Learning concepts from contexts and defenitions:A single subject replication. Journal of Reading Behaviour, 271-277.

Decarrico, J. S. (2011). vocabulary learning and teaching. In M. C. -Murcia, Teachin English as a second or foreighn language (pp. 285-298). united states: heinle\&heinle.

Ellis, R. (2001). Form focused Instruction and Language Learning. London: John Wiley and Sons Ltd.

Ellis, R. (2003). Task-based language Learning and Teaching. New York: Oxford University Press.

Ellis, R. (2004). Task-based Language Learning and Teaching. Oxford: Oxford University Press.

Ellis, R. (1994a). The Study of Second Language Acqusition. Oxford: Oxford University Press.

Freeman, D. L. (2003). Techniques and principles in language teaching. Oxford: Oxford university press.

Freeman, D. (2003). Teaching Language from Grammar to Grammaring. Canada: Tamson Heinle.

Huckin T, Haynes Mand Coady J (1993).Second Language Reading and Vocabulary Learning(Ablex Publishing Corporation) Norwood, N.J.21.

Hulstijn, J. H. (1996). “Incidental and Intentional Learning” in Handbook of Second Language Acquisition. Malden: Blackwell.

Hunt, A., \& Beglar, D. (2005). A framework for developing EFL reading vocabulary. Reading in a Foreign Language .

Jack C. Richards and Willy A. Renandya. (2002). Methodology in Language Teaching: An Anthology of Current Practice. New York: Cambridge University Press.

Knight, S. (1994). Dictionary use while reading:The effects on comprehension and vocabulary acquisition for students of different verbal abilities. The Modern Language Journal , 285-299.

Laufer, B. (1998). The development of passive and active vocabulary in a second language:Same or Different. Applied Linguistics.

Lewis, M. (2000). Teachin collocation: Further Developments in Lexical Approach. Hove:England: Language teaching publications.

Luppescu, S., \& Day, R. R. (1993). Reading, dictionaries and vocabulary learning. Language Learning , 263-287.

McCarthy, M. (1992). Vocabulary. oxford: oxford university press.

Mehring, J. G. (2005). Developing Vocabulary in Second Language Acquisition:From theories to the classroom.

Murcia, M. C. (2001). Teaching English as a second or foreign language. United states: Heilen \& Heilen.

Nation, P. (2005). Teaching and learning vocabulary. Mahwah: Erlbaum.

Nunan, D. (1989). Designing tasks for communicative classroom. Cambridge: Cambridge university press.

Nunan, D. (2006). Task-based language teaching. Cambridge: Cambridge university press.

Oxford, R. L. (2006). Task-Based Language Teaching and Learning: An Overview. Asian EFL Journal , 94.

Prabhu, S. N. (1987). Second language pedagogy. oxford: oxford university press. 
Richards, J. C., \& Renandya, W. A. (2002). Methodology in language teaching: An anthology of current practice. Cambridge: Cambridge univrsity press.

Richards, J. C., \& Rodgers, T. S. (2001). Approach and methods in language teaching. Cambridge: Cambridge university press.

Robinson, P. C. (1991). ESP today: A practitioner's guide. UK: Prentice Hall InternationalLtd.

Skehan, P. (1998). A Cognitive Approach to Language Learning. Oxford: Oxford University Press.

Skehan, P. (1996b). Second language acquisition research and Task-based instruction.

Thornbury, S. (2002). How to teach vocabulary. Edinburg Gate: Pearson Education Limited.

Ur, P. (2000). Acourse in Language Teaching:Practice and Theory. Cambridge: Cambridge University Press.

Willis, J. (1996). Aframework for task-based learning. Harlow: Longman.

Zimmerman, C. B. (1997). Historical trends in second language vocabulary instruction. NewYork: Cmbridge University Press. 